\title{
Prevalência de lesões bucais em tecidos mole e duro diagnosticadas em idosos em um serviço histopatológico de referência
}

Prevalence of oral lesions in soft and hard tissue in elderly patients in a single histopathological service Prevalencia de lesiones bucales en tejido blando y duro en ancianos diagnosticadas

en un servicio de referencia histopatológico

Annelise Lopes Cunha e SILVA ${ }^{1}$

Lioney Nobre CABRAL ${ }^{2}$

${ }^{1}$ Graduanda em Odontologia pela Universidade do Estado do Amazonas, UEA, 69065-001 Manaus - AM, Brasil

${ }^{2}$ Doutor em Biotecnologia pela Universidade Federal do Amazonas, UFAM, Professor adjunto do Curso de Odontologia, Universidade do Estado do Amazonas, UEA, 69065-001 Manaus - AM, Brasil

\section{Resumo}

O envelhecimento populacional é um fenômeno mundial, sendo percebido também no estado do Amazonas. Com a alta expectativa de vida, o enfoque na saúde geral e bucal impactam diretamente a qualidade de vida da pessoa. Desta forma, os levantamentos acerca da população geriátrica não devem ser restritos às alterações fisiológicas da idade, devendo abordar também as manifestações patológicas, retratando assim quais são as lesões bucais mais recorrentes. O trabalho em questão visa levantar o número de lesões bucais prevalentes em tecido mole e duro em idosos. Sendo feito a partir de um levantamento das lesões bucais prevalentes em tecido mole e duro que acometeram os idosos registrados nos laudos do Serviço de Patologia Oral e Maxilofacial da Universidade do Estado do Amazonas, SEPAT-UEA, entre os anos de 2012 a 2018. Segundo os dados coletados, a categoria de neoplasias de tecido mole $(28,94 \%)$ teve o maior número de casos, em que a lesão mais prevalente, sendo esta do mesmo grupo, foi a hiperplasia fibrosa inflamatória (14,04\%). Teve maior acometimento em mulheres $(54,91 \%)$, pessoas com $60-69$ anos $(74,77 \%)$, usuários de próteses removíveis $(15,56 \%)$ e a mandíbula (17,28\%) foi a localização mais comum. Com as informações adquiridas, a partir de um serviço de referência do estado do Amazonas, é possível ter um melhor direcionamento dos recursos para a população geriátrica tendo um maior enfoque para as lesões mais prevalentes visando assim uma melhor saúde bucal e consequentemente uma melhor qualidade de vida.

Descritores: Boca; Idoso; Prevalência.

\section{Abstract}

Population aging is a worldwide phenomenon, and is also noticed in the state of Amazonas. According to the high life expectancy, the focus on general health and the oral impact directly on the person's quality of life. Thus, surveys about the geriatric population should not be restricted as physiological changes in age, but should also be addressed as pathological manifestations, thus portraying which are the most recurrent oral lesions. The aim of the study is to raise the frequency of the most prevalent of oral lesions in soft and hard tissue in the elderly. Being made from a survey of oral lesions in soft and hard tissue that affected the elderly registered in the reports of the Oral and Maxillofacial Pathology Service of the Amazonas State University, SEPAT-UEA, between the years 2012 to 2018. According to collected data, the category of soft tissue neoplasms $(28.94 \%)$ had the highest number of cases, in which the most prevalent lesion, being the same group, for an inflammatory fibrous hyperplasia (14.04\%). It was more recurrent in women $(54.91 \%)$, elderly in $60-69$ years $(74.77 \%)$, users of removable prosthesis $(15.56 \%)$ and the mandible $(17.28 \%)$ was the most common location. With the information acquired, from a reference service in the state of Amazonas, it is possible to have a better targeting of resources for the geriatric population, with a greater focus on the most prevalent injuries, thus better oral health and consequently a better quality of life care.

Descriptors: Mouth; Aged; Prevalence.

\section{Resumen}

El envejecimiento de la población es un fenómeno mundial, se percibe también en el estado de Amazonas. Con la alta expectativa de vida, el enfoque en la salud general y bucal impactan directamente la calidad de vida de la persona. De esta forma, las encuestas sobre la población geriátrica no deben restringir a los cambios fisiológicos de la edad, sino que deben abordar también las manifestaciones patológicas, describiendo así cuáles son las lesiones bucales más recurrentes. El trabajo en cuestión tiene por objeto levantar el número de lesiones bucales prevalentes en tejido blando y duro en ancianos. Se realiza a partir de un estudio de las lesiones bucales prevalentes que han afectado a los ancianos registrados en los informes del Servicio de Patología Oral y Maxilofacial de la Universidad del Estado de Amazonas, SEPAT-UEA, entre los años 2012 a 2018. Según los datos recogidos, la categoría de neoplasias de tejidos blandos (28,94\%) presentó el mayor número de casos, en la que la lesión más prevalente fue la hiperplasia fibrosa inflamatoria (14,04\%). Fue más afectado por mujeres (54,91\%), personas de 60 a 69 años $(74,77 \%)$, usuarios de prótesis removibles $(15,56 \%)$ y la mandíbula $(17,28 \%)$ fue la localización más común. Con la información adquirida, de un servicio de referencia en el estado de Amazonas, es posible tener una mejor focalización de recursos para la población geriátrica, con un mayor enfoque en las lesiones más prevalentes, apuntando así a una mejor salud bucal y consecuentemente una mejor calidad de vida.

Descriptores: Boca; Anciano; Prevalencia.

INTRODUÇÃO

Os direitos destinados a pessoas com 60 anos ou mais são assegurados pelo artigo 1 , da Lei número 10.741 , de $1^{\circ}$ de outubro de 2003 do Estatuto do Idoso. Assim como, a Organização Mundial de Saúde (OMS) define que os idosos, em países desenvolvidos, tem 60 anos ou mais, já em países subdesenvolvidos é a pessoa com idade igual a 65 anos ou superior. Em que a OMS, classifica o envelhecimento agrupando os que estão entre 60-74 anos (idosos), 75-90 (anciãos) e mais de 90 anos (velhice extrema) ${ }^{1-3}$ O envelhecimento populacional é um fenômeno mundial que está acontecendo progressivamente, contudo em alguns países esse processo está muito acelerado. Por exemplo, a França demorou 150 anos (18502000) para que os indivíduos de 60 anos ou mais passassem de $10 \%$ a $20 \%$ da representatividade total demográfica, enquanto que países como China e Brasil terão o mesmo resultado em 20 anos (2000-2020; 2020-2040 respectivamente) $)^{4}$.

Segundo o Instituto Brasileiro de Geografia e Estatística (IBGE), a população 
com 65 anos ou mais em 2010 representava $7,32 \%$ dos grupos etários. É estimado que em 2020 , os idosos correspondam a $9,83 \%$ dos habitantes, como também é previsto que daqui a 40 anos seja $25,49 \%$. Levando em conta o Índice de envelhecimento (IE) durante os três anos citados, percebe-se um decréscimo entre os extremos da população retratados a partir de números aproximados, respectivamente, como: 30 idosos para cada 100 crianças até 14 anos; por conseguinte tendo índice igual a 47; e por último, 173 idosos a cada 100 crianças $^{5}$.

Enquanto que no estado do Amazonas, a população idosa em 2010 compreendia $4,01 \%$, decorridos dez anos há uma previsão de que essa estimativa evolua para 5,04\%. Assim como prediz que em 2060 os idosos compreendam 17, $29 \%$ do censo. Observando o IE entre esses três anos (2010, 2020 e 2060), respectivamente, apresentam valores aproximados a: 12 idosos a cada 100 crianças até 14 anos; índice igual a 17; e 97 idosos a cada 100 crianças sendo este de resultados quase equivalentes. Percebe-se que como visto no cenário brasileiro, o Amazonas segue a mesma tendência de envelhecimento populacional ${ }^{5}$.

De acordo com a evolução do cenário atual, a atuação médica para essa faixa etária deve ser estimulada para o diagnóstico precoce de doenças crônicas que influenciam diretamente sua qualidade de vida. Visto que, o investimento e desenvolvimento direcionados para esses setores não é suficiente, principalmente ao ressaltar que de acordo com a OMS a proporção de idosos em países em desenvolvimento é maior do que os desenvolvidos. Desta forma, grande parcela da população geriátrica não tem acesso a condições necessárias para uma saúde tanto sistêmica quanto bucal de qualidade ${ }^{6}$.

O suporte geriátrico se faz necessário por apresentarem diversas alterações tanto gerais quanto na cavidade oral podendo ser fisiológica ou patológica. As doenças mais frequentes entre os idosos são: doenças isquêmicas do coração (ênfase em insuficiência cardíaca), doenças cerebrovasculares, diabetes mellitus, doenças crônico-degenerativas (principalmente Doença de Alzheimer e de Parkinson), neoplasias tanto benignas quanto malignas, osteoporose, osteoartrose, depressão e problemas bucais. As alterações graduais da idade assim como as diversas patologias afetam diretamente a qualidade de vida geral e oral ${ }^{7}$.

Além da saúde bucal comprometida afetar o bem estar físico, psicológico e nutricional, esta pode coexistir com alguma doença sistêmica, em que estudos prévios abordam essa inter-relação e a possibilidade do comprometimento bucal propiciar ou agravar sua condição geral. Ademais, devido às suas alterações fisiológicas da idade e maior tempo de exposição a agentes nocivos, como o tabaco e álcool, os idosos estão mais sujeitos a manifestação de lesões tanto em tecido mole quanto duro ${ }^{8-10}$.

As modificações que acometem a cavidade oral ao longo do tempo compreendem a xerostomia tanto pela redução da celularidade quanto por consequência medicamentosa, retração dos tecidos periodontais de sustentação, mudanças estruturais da língua que podem afetar a capacidade gustativa, avulsão dentária podendo comprometer assim a capacidade mastigatória, diminuição da dimensão vertical, formação óssea em menor atuação e maior propensão à lesão cariosa e doenças oportunistas como a candidíase ${ }^{11-14}$.

A mucosa bucal tem a tendência a atrofiar, tornando-se brilhante e friável, por conta das mudanças degenerativas da idade como as alterações metabólicas e físicas, sendo mais suscetível a agressões externas. Consoante a isso, sua resposta imunológica também está deficitária, o indivíduo está mais vulnerável a colonização de microrganismos, principalmente fúngico, e como sua capacidade de defesa e reparação não está adequada, a superfície epitelial se torna sujeita a traumas mecânicos. Tanto mudanças normais da idade quanto fatores patológicos podem influenciar no desenvolvimento de lesões bucais ${ }^{3,12-15}$.

Estudos epidemiológicos abordando a prevalência de lesões bucais em idosos ainda são muito escassos, pois geralmente os assuntos abordados são levantamentos acerca de edentulismo, cárie dental, má oclusão, traumatismo dentário, doença periodontal ou pesquisas sobre a condição bucal do paciente, porém sem mencionar o envolvimento ou não de patologias. Enquanto que pesquisas abordando lesões bucais muitas vezes ficam restritas ao diagnóstico clínico e sem confirmação histopatológica. A análise microscópica promove um diagnóstico mais preciso e com maior confiança, em que associados a informações clínicas ajudam a estabelecer um diagnóstico mais seguro, pois muitas neoplasias malignas podem ser semelhantes, clinicamente, a lesões benignas. Sendo necessário ressaltar que os pacientes com doença de Alzheimer ou de Parkinson, devido às condições degenerativas da doença, podem estar associados a fenômenos reativos e inflamatórios a traumas crônicos e uso de 
medicamentos podendo mimetizar lesões de origem traumática ${ }^{16,17}$.

\section{Levantamentos}

epidemiológicos

baseados em análise histopatológica são relativamente raros, enquanto muitos levantamentos focam somente o carcinoma espinocelular e não levam em consideração a existência de outras lesões intrabucais. Além disso, é de extrema importância a execução desse tipo de pesquisa tanto pela sua escassez literária quanto por promover informações precisas e seguras sobre a condição do paciente $6,10,18$.

É necessário ressaltar que a saúde geral do indivíduo não está separada da bucal e que a intervenção odontológica contribui para a prevenção e redução da incidência de várias doenças. Dessa forma, a execução de estudos sobre a prevalência de lesões que acometem a população de estudo que nesse caso é a idosa, ajudam também a entender a extensão e a gravidade dessas doenças podendo avaliar seu estado e caracterizar a condição da saúde oral. Como também ajudam a realizar um planejamento mais abrangente e com um melhor direcionamento, visando melhorar a forma de atendimento para a população geriátrica voltadas para prevenção e tratamento ${ }^{6,8,18}$.

\section{MATERIAL E MÉTODO}

Este trabalho consiste em um estudo retrospectivo, observacional, descritivo, de prevalência visando determinar a frequência de lesões bucais em tecido mole e duro em idosos registrados nos laudos do Serviço de Patologia Oral e Maxilofacial da Universidade do Estado do Amazonas, SEPAT-UEA, entre os anos de 2012 a 2018. A pesquisa incluiu os laudos correspondentes apenas à faixa etária igual ou superior a 60 anos, sem distinção de gênero, etnia e procedência. Como também descartou os que não continham informações cruciais como idade, lesão e sexo.

Diante das liberações de laudos histopatológicos foram contabilizados 1656 laudos. Desse quantitativo geral, o universo senil compreende 224 fichas. Para esse levantamento epidemiológico foram registradas informações referentes à faixa etária, gênero dos pacientes, consistência da peça biopsiada, localização anatômica, portador ou não de prótese dentária e diagnóstico histopatológico. As lesões foram agrupadas por categorias segundo Neville et al. ${ }^{19}$, com modificações, sendo classificadas em: Defeitos do Desenvolvimento da Região Oral e Maxilofacial, Doença Pulpar e Periapical, Doenças
Periodontais, Lesões físicas e Químicas, Doenças Alérgicas e Imunológicas, Patologia Epitelial, Patologia das Glândulas Salivares, Neoplasias de Tecidos Moles, Patologia Óssea, Cistos e Tumores Odontogênicos, Doenças Dermatológicas, Doenças Infecciosas, Lesão inflamatória Proliferativa e Doenças Hematológicas.

As implicações éticas do estudo referiram-se à confidencialidade na coleta dos dados e ao anonimato dos participantes na apresentação dos resultados, seguindo as orientações da Resolução 466/2012 do Conselho Nacional de Saúde que regulamenta a pesquisa em seres humanos, cuja apreciação foi submetida ao Comitê de Ética em Pesquisa da Universidade Estadual do Amazonas (UEA) e aprovado mediante Parecer no 3.332.747.

RESULTADOS

Entre os laudos histopatológicos, cerca de 224 fichas $(13,53 \%)$ foram selecionadas de acordo com os critérios de inclusão e exclusão listados, em que 1209 (73\%) configuram indivíduos com menos de 60 anos. Dentre as informações observadas, verificou-se que 223 $(13,47 \%)$ não continham informações cruciais como a faixa-etária e diagnóstico da lesão, sendo assim excluídos da coleta de dados.

Para a análise de dados, foram organizados três grupos de acordo com a faixa etária: 60-69 anos; 70-79 anos e 80 anos ou mais. Visto que, foi observado uma maior prevalência de pessoas da sexta década de vida $(74,77 \%)$ (Tabela 1$)$

Tabela 1. Distribuição dos grupos etários de acordo com os anos

\begin{tabular}{c|c|c|c|c}
\hline \hline \multirow{2}{*}{ Ano } & \multicolumn{4}{|c}{ Faixa Etária (N) } \\
\cline { 2 - 5 } & $\begin{array}{c}60-69 \\
\text { anos }\end{array}$ & $\begin{array}{c}\mathbf{7 0 - 7 9} \\
\text { anos }\end{array}$ & $\begin{array}{c}\mathbf{8 0} \text { anos } \\
\text { ou mais }\end{array}$ & Total \\
\hline 2012 & 8 & 1 & 1 & $\mathbf{1 0}$ \\
\hline 2013 & 19 & 4 & 0 & $\mathbf{2 3}$ \\
\hline 2014 & 11 & 2 & 1 & $\mathbf{1 4}$ \\
\hline 2015 & 19 & 6 & 2 & $\mathbf{2 7}$ \\
\hline 2016 & 27 & 9 & 1 & $\mathbf{3 7}$ \\
\hline 2017 & 42 & 7 & 8 & $\mathbf{5 7}$ \\
\hline 2018 & 42 & 12 & 2 & $\mathbf{5 6}$ \\
\hline Total & $\mathbf{1 6 8}$ & $\mathbf{4 1}$ & $\mathbf{1 5}$ & $\mathbf{2 2 4}$ \\
\hline *N- Núm &
\end{tabular}

Entre os anos listados, verificou-se uma maior parcela feminina $(54,91 \%)$ em comparação com a masculina $(45,09 \%)$. Foi também analisado sobre a natureza do tecido biopsiado, se era de caráter mole, duro ou ambos. O tipo de qualidade da peça mais prevalente foi o de tecido mole $(89,73 \%)$, em seguida tanto tecido duro quanto mole $(5,80 \%)$ e por último, o tecido duro com representação de $4,47 \%$. 
A localização anatômica mais frequente foi em região de mandíbula $(17,28 \%)$. Em seguida, verificou-se grande acometimento do palato duro $(13,17 \%)$ e língua $(10,70 \%)$, tendo um maior número em borda lateral $(5,35 \%)$. Observou-se também que muitas vezes a lesão acometeu mais de um sítio anatômico (Tabela 2).

Tabela 2. Dez localizações anatômicas mais recorrentes.

\begin{tabular}{c|c|c}
\hline \hline \multicolumn{2}{|c|}{ Localização anatômica } & N (\%) \\
\hline 1. & Mandíbula & $42(17,28)$ \\
\hline 2. & Palato duro & $32(13,17)$ \\
\hline 3. & Língua & $26(10,70)$ \\
\hline 4. & Mucosa jugal & $25(10,29)$ \\
\hline 5. & Não Informado & $25(10,29)$ \\
\hline 6. & Maxila & $23(9,46)$ \\
\hline 7. & Lábio inferior & $22(9,05)$ \\
\hline 8. & Assoalho bucal & $16(6,58)$ \\
\hline 9. & Lábio superior & $12(4,94)$ \\
\hline 10. & Palato mole & $9(3,70)$ \\
\hline
\end{tabular}

${ }^{*} \mathrm{~N}$ - Número de casos

Como é descrito na literatura, os idosos são a grande maioria em relação aos usuários de prótese dentária, em que estas quando mal adaptadas ou confeccionadas podem levar ao desenvolvimento de lesões bucais. Sendo assim, verificou- se que 47 pessoas $(20,89 \%)$ faziam uso de algum tipo de peça protética. As próteses removíveis foram as mais frequentes, equivalentes a 15,56\% da amostra. Cerca de $16,44 \%$ de mulheres utilizaram algum artefato, enquanto que homens corresponderam a $4,44 \%$. A faixa etária mais representativa foi a de 60-69 anos (14,67\%) (Tabela 3).

Tabela 3. Distribuição das categorias de prótese dentária relacionadas com a faixa etária.

\begin{tabular}{|c|c|c|c|c|}
\hline Categoria & $\begin{array}{l}60-69 \\
\text { anos }\end{array}$ & $\begin{array}{l}70-79 \\
\text { anos }\end{array}$ & $\begin{array}{l}80 \text { anos } \\
\text { ou mais }\end{array}$ & $\begin{array}{l}\text { Total } \\
\text { (N; \%) }\end{array}$ \\
\hline Fixa & 1 & - & - & $1(0,44)$ \\
\hline Removível & 25 & 5 & 5 & $\begin{array}{c}35 \\
(15,56)\end{array}$ \\
\hline $\begin{array}{l}\text { Prótese não } \\
\text { delimitada }\end{array}$ & 7 & 3 & 1 & $11(4,89)$ \\
\hline $\begin{array}{c}\text { Não } \\
\text { Informado }\end{array}$ & 135 & 34 & 9 & $\begin{array}{c}178 \\
(79,11)\end{array}$ \\
\hline Total (N) & $\begin{array}{c}168 \\
(74,67)\end{array}$ & $\begin{array}{c}42 \\
(18,67)\end{array}$ & $\begin{array}{c}15 \\
(6,66)\end{array}$ & $225(100)$ \\
\hline
\end{tabular}

O grupo de neoplasias de tecido mole foi o mais frequente $(28,94 \%)$, tendo maior acometimento em idosos da sexta década de vida $(21,70 \%)$. Seguido por patologia epitelial $(24,68 \%)$ e patologia das glândulas salivares $(13,62 \%)$. A lesão mais prevalente foi a hiperplasia fibrosa inflamatória $(14,04 \%)$, seguida pelo carcinoma espinocelular $(10,21 \%)$ e leucoplasia (5,96\%). Verificou-se que muitos idosos apresentaram mais de uma lesão, ou no mesmo sítio ou em localidades diferentes, entretanto neste preste estudo a ocorrência de mais de uma lesão ocorreu na mesma localização (Tabelas 4 a 6).

Tabela 4. Distribuição das categorias das lesões segundo Neville et al. ${ }^{19}$

\begin{tabular}{c|c}
\hline Categoria das lesões segundo Neville et al. (2016) & N (\%) \\
\hline \hline $\begin{array}{c}\text { Defeitos do Desenvolvimento da Região Oral e } \\
\text { Maxilofacial }\end{array}$ & $9(3,83)$ \\
\hline $\begin{array}{c}\text { Doença Pulpar e Periapical } \\
\text { Doenças Periodontais } \\
\text { Lesões fisicas e quimicas }\end{array}$ & $10(4,25)$ \\
\hline Doenças alérgicas e imunológicas & $7(2,98)$ \\
\hline Patologia Epitelial & $13(5,53)$ \\
\hline Patologia das glândulas salivares & $3(1,28)$ \\
\hline Neoplasias de Tecidos Moles & $58(24,68)$ \\
\hline Patologia óssea & $32(13,62)$ \\
\hline Cistos e tumores odontogênicos & $68(28,94)$ \\
\hline Doenças dermatológicas & $7(2,98)$ \\
\hline Doenças infecciosas & $7(2,98)$ \\
\hline Lesão inflamatória proliferativa & $2(0,85)$ \\
\hline Doenças Hematológicas & $6(2,55)$ \\
\hline $\begin{array}{c}\text { Biópsia com aspecto de normalidade } \\
\text { Diagnóstico Inconclusivo/Laudo descritivol } \\
\text { Material não representativo para análise }\end{array}$ & $2(0,85)$ \\
\hline Total & $2(0,85)$ \\
\hline
\end{tabular}

^N- Número de casos

Tabela 5. Dez lesões bucais mais frequentes associadas com o número de casos e sexo.

\begin{tabular}{|c|c|c|c|}
\hline & Diagnóstico & $\mathrm{N}(\%)$ & $\operatorname{Sexo}(N ; \%)$ \\
\hline 1. & $\begin{array}{l}\text { Hiperplasia Fibrosa } \\
\text { Inflamatória }\end{array}$ & $\begin{array}{c}33 \\
(14,04)\end{array}$ & $\begin{array}{c}F(22 ; 9,36) \text { e } M(11 ; \\
4,68)\end{array}$ \\
\hline 2. & $\begin{array}{l}\text { Carcinoma } \\
\text { Espinocelular }\end{array}$ & $\begin{array}{c}24 \\
(10,21)\end{array}$ & $\begin{array}{c}\mathrm{F}(12 ; 5,11) \text { e } \mathrm{M}(12 ; \\
5,11)\end{array}$ \\
\hline 3. & Leucoplasia & $14(5,96)$ & $\begin{array}{c}\mathrm{F}(7 ; 2,98) \text { e } \mathrm{M}(7 ; \\
2,98)\end{array}$ \\
\hline 4. & $\begin{array}{l}\text { Sialoadenite } \\
\text { Esclerosante } \\
\text { Crônica }\end{array}$ & $11(4,68)$ & $\begin{array}{c}\mathrm{F}(9 ; 3,83) \text { e } \mathrm{M}(2 ; \\
0,85)\end{array}$ \\
\hline 5. & $\begin{array}{l}\text { Fibroma de células } \\
\text { gigantes }\end{array}$ & $9(3,83)$ & $\begin{array}{c}\mathrm{F}(7 ; 2,98) \text { e } \mathrm{M}(2 ; \\
0,85)\end{array}$ \\
\hline 6. & Queilite Actinica & $6(2,55)$ & $\begin{array}{c}\mathrm{F}(2 ; 0,85) \text { e } \mathrm{M}(4 ; \\
1,70)\end{array}$ \\
\hline 7. & $\begin{array}{l}\text { Cisto periodontal } \\
\text { apical/ radicular }\end{array}$ & $5(2,12)$ & $\begin{array}{c}\mathrm{F}(1 ; 0,42) \text { e } \mathrm{M}(4 ; \\
1,70)\end{array}$ \\
\hline 8. & $\begin{array}{l}\text { Morsicatio } \\
\text { Buccarum }\end{array}$ & $5(2,12)$ & $\begin{array}{c}\mathrm{F}(2 ; 0,85) \text { e } \mathrm{M}(3 ; \\
1,27)\end{array}$ \\
\hline 9. & $\begin{array}{l}\text { Ceratose /queratose } \\
\text { friccional }\end{array}$ & 5( & $\begin{array}{c}\mathrm{F}(2 ; 0,85) \text { e } \mathrm{M}(3 ; \\
1,27)\end{array}$ \\
\hline 10 & $\begin{array}{l}\text { Granuloma } \\
\text { Periapical }\end{array}$ & $4(1,70)$ & $F(4 ; 1,70)$ e $M(0)$ \\
\hline
\end{tabular}

${ }^{\star} \mathrm{N}$ - Número de casos; F- Feminino; M- Masculino

Tabela 6. Dez lesões bucais mais frequentes associadas com a faixa etária

\begin{tabular}{|c|c|c|}
\hline \multicolumn{2}{|r|}{ Diagnóstico } & Idade (N; \%) \\
\hline 1. & $\begin{array}{l}\text { Hiperplasia Fibrosa } \\
\text { Inflamatória }\end{array}$ & $\begin{array}{c}\text { 60-69 anos }(25 ; 10,63), 70-79 \\
\text { anos }(5 ; 2,13), 80 \text { anos ou mais } \\
(3 ; 1,28)\end{array}$ \\
\hline 2. & $\begin{array}{l}\text { Carcinoma } \\
\text { Espinocelular }\end{array}$ & $\begin{array}{c}60-69 \text { anos }(9 ; 3,83), 70-79 \\
\text { anos }(9 ; 3,83) \text { e } 80 \text { anos ou } \\
\text { mais }(6 ; 2,55)\end{array}$ \\
\hline 3. & Leucoplasia & $\begin{array}{c}60-69 \text { anos }(11 ; 4,68), 70-79 \\
\text { anos }(2 ; 0,85) \text { e } 80 \text { anos ou } \\
\text { mais }(1 ; 0,42)\end{array}$ \\
\hline 4. & $\begin{array}{c}\text { Sialoadenite } \\
\text { Esclerosante Crônica }\end{array}$ & $\begin{array}{c}\text { 60-69 anos }(9 ; 3,83), 70-79 \\
\text { anos }(2 ; 0,85)\end{array}$ \\
\hline 5. & $\begin{array}{c}\text { Fibroma de células } \\
\text { gigantes }\end{array}$ & $\begin{array}{c}\text { 60-69 anos }(5 ; 2,12), 70-79 \\
\text { anos }(3 ; 1,28), 80 \text { anos ou mais } \\
(1 ; 0,42)\end{array}$ \\
\hline 6. & Queilite Actínica & $60-69$ anos $(6 ; 2,55)$ \\
\hline 7. & $\begin{array}{l}\text { Cisto periodontal } \\
\text { apical/ radicular }\end{array}$ & $\begin{array}{c}60-69 \text { anos }(3 ; 1,28) \text { e } 70-79 \\
\text { anos }(2 ; 0,85)\end{array}$ \\
\hline 8. & Morsicatio Buccarum & $\begin{array}{c}\text { 60-69 anos }(3 ; 1,28) \text { e } 70-79 \\
\text { anos }(2 ; 0,85)\end{array}$ \\
\hline 9. & $\begin{array}{c}\text { Ceratose /queratose } \\
\text { friccional }\end{array}$ & $\begin{array}{c}60-69 \text { anos }(4 ; 1,70) \text { e } 70-79 \\
\text { anos }(1 ; 0,42)\end{array}$ \\
\hline 10 & Granuloma Periapical & $60-69$ anos $(4 ; 1,70)$ \\
\hline
\end{tabular}


DISCUSSÃO

O levantamento de dados

epidemiológicos em idosos, principalmente em casos de patologias bucais, proporcionam um direcionamento mais focalizado, visto que muitos estudos enfatizam o diagnóstico clínico estando vulnerável a lesões com aparência clínica semelhante. A presente pesquisa coletou informações contidas nos laudos histopatológicos do SEPAT-UEA, recrutando registros de repartições públicas, visto que o laboratório em questão é um local de referência para o estado. Desta forma, a partir dos dados coletados, é possível ter uma nova perspectiva sobre o acometimento de lesões bucais em idosos, em virtude da baixa quantidade de estudos sobre este assunto na literatura.

Houve um maior número de casos de mulheres, em concordância com o que já havia sido apontado por Esteves et al. ${ }^{20}$ e Silva et al. $^{21}$. Estudos anteriores demonstram que a parcela do público feminino representa o principal grupo que busca tratamento odontológico, além disso a população idosa tem uma grande representação feminina também conferindo a denominação de "feminização do envelhecimento", este fenômeno é devido a menor taxa de mortalidade entre as mulheres ${ }^{10}$.

A localização anatômica mais frequente foi a mandíbula $(17,28 \%)$, seguido pelo palato duro $(13,17 \%)$, língua $(10,70 \%)$ e a mucosa jugal $(10,29 \%)$. Entre os casos em língua, a borda lateral $(5,35 \%)$ foi a mais recorrente e muitos não delimitaram a área lingual acometida $(3,29 \%)$. No estudo de Rohini et al. ${ }^{10}$, o sítio anatômico mais prevalente foi a mucosa jugal assim como visto por Carvalho et al. ${ }^{18}$, enquanto que houve similaridade nas outras localidades anatômicas encontradas.

A região mandibular abrangeu casos intraósseos e de tecido mole, incluindo áreas como: região periapical, papila dental, região submentual, região retromolar, fundo de vestíbulo e região de mento. Para Silva et al. ${ }^{16}$, a mandíbula também foi a localização mais prevalente, limitando-se a casos intraósseos.

Como visto no levantamento de Silva et al. ${ }^{21}$, o Brasil é um país com alto índice de edentulismo sendo 0 uso de próteses removíveis e fixas bastante comuns, principalmente entre os indivíduos com mais de 60 anos. Neste estudo, as próteses removíveis foram as mais frequentes, equivalentes 15,56\% da amostra, correspondendo a: prótese total (PT) não especificada, PT superior (a mais prevalente), PT inferior, PT superior e inferior, prótese parcial removível (PPR) superior e PPR não delimitada. Cerca dos 47 pacientes que utilizavam alguma peça protética, 21 deles tinham como diagnóstico uma das dez lesões mais frequentes, como: hiperplasia fibrosa inflamatória, carcinoma espinocelular, fibroma de células gigantes, leucoplasia, sialoadenite esclerosante crônica, queratose friccional e morsicatio buccarum. Não se pode afirmar que - uso da prótese estava relacionado diretamente com a presença da patologia, visto que o laudo histopatológico muitas vezes não informava o tempo de uso da peça ou se estava mal adaptada ou causando alguma injúria ao local.

Foi observada a presença de um caso de nematodíase bucal associada a PT superior em região de palato duro, pode-se inferir que a prótese em questão não tinha uma higienização efetiva ou não era removida para ser higienizada, o que durante a alimentação poderia abrigar restos de comida que levaram ao desenvolvimento larval do parasita. Como se tratava de uma PT superior, o íntimo contato com o palato duro propiciou a progressão da patologia. Houve outros casos de nematodíase bucal e ancilostomíase oral, entretanto não se pode relacionar com o uso de prótese, visto que não foi informado no laudo. O alto número do tópico "não informado" $(79,11 \%)$ na categoria de usuário de prótese ressalta a importância de uma padronização em relação ao preenchimento do laudo histopatológico, visto que a falta de informação deixa sugestivo se o paciente pode ser portador de alguma peça protética ou o operador deixou de fornecer este dado.

Dessa forma, é necessário ressaltar a importância da orientação ao paciente e aos cuidadores de indivíduos com alguma dificuldade motora ou limitação por doenças como Alzheimer e Parkinson em relação a higiene oral. A falta de informação ou recursos influencia diretamente na qualidade da saúde bucal quanto sistêmica, em que uma má higienização, principalmente associada ao uso de próteses, é um fator irritativo que propicia o desenvolvimento de várias lesões, como as cariosas e as doenças periodontais ${ }^{1,23}$.

A hiperplasia fibrosa inflamatória (HFI) foi a lesão mais recorrente entre os anos 2012 a 2018, concordando com os dados apresentados em estudos prévios feitos por Canedo ${ }^{1}$, Silva et al. ${ }^{21}$ e Sassi et al. ${ }^{24}$. Esta patologia estava muito relacionada com os pacientes que usavam algum tipo de prótese, principalmente as próteses totais. Percebeu-se que a HFI teve acometimento em diversos sítios da cavidade oral, sendo que a mucosa jugal e o palato duro foram os mais prevalentes. Em seguida, o 
carcinoma espinocelular foi a segunda lesão mais frequente, semelhante ao que foi encontrado por Fonseca et al. ${ }^{25}$.

No Brasil, o câncer de cabeça e pescoço representa a quinta neoplasia mais comum no país. Segundo estimativas do Instituto Nacional de Câncer (INCA) para o ano de 2020, o câncer de cavidade oral ocupará a quinta posição entre as neoplasias mais incidentes entre o sexo masculino e a décima terceira entre o sexo feminino. No presente estudo houve um equilíbrio entre os gêneros, sendo que ambos apresentaram $5,11 \%$ de acometimento ${ }^{26,27}$.

O carcinoma espinocelular (CEC) ocorre em $95 \%$ dos casos na cavidade oral em que o risco de desenvolver essa neoplasia aumenta de acordo com o envelhecimento. De acordo com estimativas do INCA para 2020, o município de Manaus ocupa a quinta posição entre as capitais com maiores casos para câncer bucal. Durante a coleta de dados houve uma distribuição equilibrada entre os grupos de faixa etária, acometimento em diversos sítios anatômicos e diagnóstico do CEC em diferentes estadiamentos, o que a análise por microscopia possibilita essa identificação, diferentemente dos levantamentos somente por exame clínico. A região de palato foi a mais frequente, em que geralmente as neoplasias de cavidade oral tem uma identificação facilitada por conta da melhor visualização, entretanto como detectado por Almeida et al. $^{28}$, essas patologias são diagnosticadas tardiamente e muitas vezes sem possibilidade de tratamento ${ }^{27}$.

A presença de lesões potencialmente malignas como: leucoplasia (5,96 \%), queilite actínica (2,55\%) e eritroplasia (0,85\%) diagnosticadas com a presença ou não de displasia epitelial, ressalta a importância do acompanhamento pelo cirurgião dentista e colaboração do paciente para um melhor prognóstico do tratamento. Neste estudo, a leucoplasia configura entre as três lesões mais frequentes, concordando com Rohini et al. ${ }^{11} \mathrm{e}$ Fonseca et al. ${ }^{25}$. Esta lesão cancerizável muitas vezes não é detectada ou a biópsia é negligenciada e em grande parte desses casos podem evoluir para um carcinoma.

CONCLUSÃO

A categoria de neoplasias de tecido mole teve o maior número de casos, em que a lesão mais prevalente, sendo esta do mesmo grupo, foi a hiperplasia fibrosa inflamatória, seguido por carcinoma espinocelular e leucoplasia. As mulheres tiveram a maior representação e as pessoas com 60-69 anos foram as mais frequentes. A mandíbula foi a localização mais comum e as próteses removíveis foram as mais recorrentes.

A falta de uniformidade apresentada em alguns laudos histopatológicos ao apresentar o resumo clínico dificulta o processo de coleta de dados. Esta deficiência impossibilita uma maior padronização e informações mais completas, visto que muitos registros não foram selecionados por falta de dados cruciais como a idade ou se enquadraram no tópico de "não informado".

Esse tipo de estudo possibilita informações mais fidedignas, pois a avaliação é feita a partir de uma descrição do quadro clínico contido no laudo e o fragmento biopsiado para a análise histopatológica a fim de conseguir estabelecer um diagnóstico mais confiável, visto que somente a aparência clínica pode ser semelhante a outras lesões não conferindo um critério muito seguro.

Com as informações coletadas a partir de um serviço de referência do estado do Amazonas, é possível ter um melhor direcionamento dos recursos para a população geriátrica tendo um maior enfoque para as lesões mais prevalentes visando assim uma melhor saúde bucal e consequentemente uma melhor qualidade de vida. A quantidade de estudos a partir de análise microscópica é baixa e é necessário estimular a propagação desse tipo de pesquisa para ter um compilado de informações mais fidedignas.

REFERÊNCIAS

1. Canedo GN. Prevalência de patologias bucais em pacientes de terceira idade. 2010.

2. Brasil. Lei 10.741/2003. Estatuto do Idoso. Brasília: DF, 1ํ de outubro de 2003.

3. Mahdani FY, Radithia D, Parmadiati AE, Ernawati DS. Prevalence of oral mucosal lesions in geriatric patients in Universitas Airlangga Dental Hospital. Acta Medica Philippina. 2019;53(5):407-11.

4. DESA UN. United Nations, Department of Economic and Social Affairs, Population Division. World Population Prospects 2019: Highlights. 2019.

5. Instituto Brasileiro de Geografia e Estatística. Projeção da população do Brasil e das Unidades de Federação. Amazonas: IBGE; 2018.

6. Owlia F, Bahadori L, Ahadian H, Hakimian R, Kazemein SK. Prevalence of Chronic Diseases in Elderly Living in Yazd Nursing Homes, and Its Relations with Oral Soft Tissue Lesions (OSTL). JCHR. 2019;8(4):196-202.

7. Chaimowicz F, Barcelos EM, Madureira MDS, Ribeiro MTF. Saúde do Idoso. $2^{\circ}$ edição- Belo Horizonte: NESCON, UFMG; 2013. 
8. Crovador CJ, Mansani FP, Bernardi LG, Soares LS, Grande RS. Lesões bucais mais comuns em idosos e seus tratamentos. J Health. 2020;23(1).

9. Dias ACMS, Medeiros AMC, Freitas YNL, Lima KC, Maia PRL, Oliveira PT. Achados radiográficos em radiografias panorâmicas de idosos: estudo transversal em 1006 pacientes. Rev port estomatol med dent cir maxilofac. 2019;60(2):59-65.

10. Rohini S, Sherlin HJ, Jayaraj G. Prevalence of oral mucosal lesions among elderly population in Chennai: a survey. J Oral Med Oral Surg. 2020;26(1):1-5.

11. Albeny AL, Santos DBF. Doenças bucais que mais acometem o paciente na terceira idade: uma revisão de literatura. Id on Line Rev. Mult. Psic. 2018;12(42):681-94.

12. Silva RGN, Salvio LA, Miranda AF. Alterações bucais na terceira idade: uma realidade clínica do futuro cirurgião dentista. Breves considerações. Rev Longeviver. 2012;24:53-60.

13. Ribeiro DG, Silva MM, Nogueira SS, Arioli Filho JN. A saúde bucal na terceira idade. Salusvita. 2009;28(1):101-11.

14. Moraes CV, Albuquerque LC, Chevitarese L. A importância da Odontogeriatria para a oferta de cuidado bucais aos idosos. Rede de Cuidados em Saúde.2017;10(1):1-9.

15. Yadav NR, Jain M, Sharma A, Yadav R, Pahuja $M$, Jain V. Distribution and prevalence of oral mucosal lesions in residents of old age homes in Delhi, India. Nepal J Epidemiol. 2018; 8(2):727-34.

16. Silva HPRD, Koppe B, Brew MC, Sória GS, Bavaresco CS. Approach to the most prevalent oral disorders among the elderly: an integrative review focusing on primary health care. Rev bras geriatr gerontol. 2017;20(3):432-43.

17. El Toum S, Cassia A, Bouchi N, Kassab Y. Prevalence and distribution of oral mucosal lesions by sex and age categories: A retrospective study of patients attending lebanese school of dentistry. Int J Dent. 2018: 4030134.

18. Carvalho IKF. Análise clínico-patológica de lesões orais em uma população geriátrica brasileira [dissertação]. Recife: Universidade Federal de Pernambuco; 2017.

19. Neville BW, Damm DD, Allen CM, Bouquot JE. Patologia Oral e Maxilofacial. 4.ed.Rio de Janeiro: Elsevier; 2016

20. Esteves RA, Igarashi $A B$, Conceição $C A F$, Celestino Júnior AF, Athayde Al. Prevalência das lesões bucais em usuários de próteses removíveis. PCL. 2005;7(36):147-53.

21. Silva LP, Leite RB, Sobral APV, Arruda JA, Oliveira LV, Noronha MS et al. Oral and maxillofacial lesions diagnosed in older people of a brazilian population: a multicentric study. $J$ Am Geriatr Soc. 2017;65(7):1586-590.

22. Silva ET, Oliveira RT, Leles CR. Fatores associados ao edentulismo funcional em idosos brasileiros. Com Ciências Saúde. 2016; 27(2):129-38.

23. Bomfim RP et al. Prevalência de Lesões de Mucosa Bucal em Pacientes Portadores de Prótese Dentária. Pesqui bras odontopediatria clín. integr. 2008;8(1):117-21,

24. Sassi LM, Patussi C, Ramos GHA, Bixofis RB, Schussel JL, Guebur MI. Prevalence of oral lesions in elderly patients on oral cancer prevention campaigns in Paraná state Brazil 1989- 2013. Braz Dent Sci. 2014;17(3):27-31.

25. Fonseca MF, Kato CO, Pereira MC, Gomes LT, Abreu LG, Fonseca FP et al. Oral and maxillofacial lesions in older individuals and associated factors: A retrospective analysis of cases retrieved in two different services. J Clin Exp Dent. 2019;11(10):e921-e29.

26. Alvarenga LM, Ruiz MT, Pavarino-Bertelli EC, Ruback MJC, Maniglia JV, Bertollo MG. Avaliação epidemiológica de pacientes com câncer de cabeça e pescoço em um hospital universitário do noroeste do estado de São Paulo. Rev Bras Otorrinolaringol. 2008;74(1): 58-73.

27. Instituto Nacional de Câncer José Alencar Gomes da Silva. Estimativa 2020: incidência de câncer no Brasil / Instituto Nacional de Câncer José Alencar Gomes da Silva. - Rio de Janeiro: INCA, 2019.

28. Almeida OP. Patologia Oral. São Paulo: Artes Médicas, 2016. Série Abeno: Odontologia Essencial - Parte Básica.

\section{CONFLITO DE INTERESSES}

Os autores declaram não haver conflitos de interesse

AUTOR PARA CORRESPONDÊNCIA

\section{Annelise Lopes Cunha e Silva}

Avenida Visconde de Porto Seguro, quadra 3A, Número 7

69058-090 Manaus - AM, Brasil

E-mail: annelopesc@gmail.com 